\title{
MODERNIZAÇÃO DA GESTÃO PÚBLICA, REFORMA EDUCACIONAL E AVALIAÇÃO NO RIO GRANDE DO NORTE \\ http://dx.doi.org/10.5902/2318133867316
}

\author{
Antônia Bruna da Silva ${ }^{1}$ \\ Girlene Pereira da Silva²
}

\begin{abstract}
Resumo
Este estudo teve por objetivo abordar aspectos estruturantes da reforma educacional deflagrada pelo Estado do Rio Grande do Norte, no âmbito do Projeto RN Sustentável, situando a implantação do Sistema Integrado de Monitoramento e Avaliação Institucional da Secretaria de Estado da Educação do Rio Grande do Norte. A análise foi desenvolvida a partir de uma pesquisa documental empreendida em sítios oficiais do Executivo estadual e no site do próprio sistema de avaliação. A reforma educacional em curso no Estado do Rio Grande do Norte integra um vasto projeto de modernização da gestão pública, que prevê uma série de medidas de viés gerencialista para o campo educacional, como é o caso do sistema de avaliação externa voltado à rede estadual de ensino básico.

Palavras-chave: modernização administrativa; reforma da educação; avaliação da educação básica.
\end{abstract}

\section{MODERNIZATION OF PUBLIC MANAGEMENT, EDUCATIONAL REFORM AND EVALUATION IN RIO GRANDE DO NORTE}

\begin{abstract}
This study aims to unveil structural aspects of the educational reform advocated by the state of Rio Grande do Norte in the context of the RN Sustentável Project, situating the implementation of the Integrated System of Institutional Monitoring and Evaluation of the State Department of Education of Rio Grande do Norte. The analysis was developed from a documental research undertaken in official sites of the State Executive and in the site of the evaluation system. The ongoing educational reform in the state integrates a project of modernization of public management, providing for a series of measures of managerialist bias for the education, as is the case of the system of external evaluation aimed at the state network of basic education.

Key-words: administrative modernization; education reform; evaluation of basic education.
\end{abstract}

\footnotetext{
1 Universidade do Estado do Rio Grande do Norte, Brasil. E-mail: antoniabruna@uern.br.

2 Prefeitura Municipal de Pereiro/CE, Brasil. E-mail: girlenesilva@prof.edu.pereiro.ce.gov.br. 


\section{Introdução}

D Brasil as avaliações externas e de larga escala, que começaram a ser implantadas a partir de 1990, se tornaram presentes no contexto educacional, sendo apresentadas pelos diferentes governos como um meio para subsidiar, avaliar ou fortalecer políticas e práticas educativas e, principalmente, como uma estratégia para aquilatar e melhorar a qualidade da educação.

Não obstante, mais do que a implantação de um sistema de avaliação, a proposição desse tipo de mecanismo se relaciona com a implantação de um modelo político-administrativo no campo educacional, cuja lógica demanda a existência da avaliação de desempenho. No território brasileiro, assim como em vários países do mundo, os sistemas de avaliação da educação básica são uma das peças essenciais de determinadas reformas educacionais provenientes de reformas do aparelho do Estado, defendidas a partir da década de 1980.

Isso posto, a adoção do novo modelo de gestão pública, no plano da educação e dos demais setores sociais, está vinculada à redefinição do papel do Estado no âmbito dos serviços públicos (Castro, 2007). Em muitos dos casos tais reformas são introduzidas por intermédio da alegação da ineficiência do modelo burocrático de gestão, acompanhada pela defesa da necessidade de modernização da administração pública, que, de acordo com Afonso (2001), também vem sendo sugerida "por expressões como reinvenção do governo, acção administrativa orientada para os resultados, new public management, entre outras" (p. 24).

Em linhas gerais, da sua versão inicial até seu formato mais atual, o modelo gerencial, como também é o caso das reformas de Estado inspiradas nele, preceitua uma série de orientações e princípios, caracterizando-se pela defesa da redução e controle dos gastos públicos e pela busca da eficiência governamental e da melhoria da qualidade dos serviços ofertados. Para tanto, a adesão à descentralização administrativa, à administração por objetivos, bem como a mecanismos de racionalização orçamentária, de avaliação de desempenho, de competição administrada e de responsabilização, faz-se essencial. Além dessas medidas, mais recentemente passou-se a valorizar a noção de esfera pública como espaço de transparência e de participação dos cidadãos, dando realce à questão da cooperação, da justiça e da equidade na prestação de serviços públicos (Abrucio, 2005; Cabral Neto, 2009; Castro, 2007; Paula; Costa; Lima, 2019).

$O$ fato é que esse modelo se alastra por diversos países, repercutindo sobre os diferentes setores da máquina estatal. No campo educacional a influência é de tamanha proporção que, "desde os sistemas centrais até à escola, passam a ser adotadas diretrizes gerenciais na condução dos serviços educacionais" (Castro, 2007, p. 131). Nessa linha, ainda em conformidade com a autora, o ideário da modernização da gestão vem sendo incluído no cerne das reformas educativas como um mecanismo para promover o sucesso escolar, em que tal modernização implica uma gestão baseada em resultados e indicadores de desempenho. Em virtude disso, por exemplo, Lessard (2009) se refere à política educativa baseada na evidência.

Tendo como matriz ideológica o arranjo gerencial mundialmente difundido, tais ideias adentraram o plano educacional brasileiro ainda no final do século 20. Nesse período, consoante Cabral Neto (2009), ganhou centralidade na agenda educacional do país a necessidade de modernizar o padrão de gestão dos sistemas educacionais até

\begin{tabular}{|l|l|l|l|l|l|}
\hline Regae: Rev. Gest. Aval. Educ. & Santa Maria & v. 10 & n. 19 & e67316, p. 1-17 & 2021 \\
\hline
\end{tabular}


então instituído. Assim, por meio das reformas educativas que passaram a ser implantadas com esse propósito a partir dos anos 1990, sobressaiu-se a preocupação com a melhoria da eficácia e eficiência dos sistemas educativos, fazendo-se essenciais, para tanto, a descentralização, a participação dos usuários nos serviços públicos educacionais, juntamente com os mecanismos de responsabilização educacional.

A eficácia ou a qualidade dos serviços públicos nesse direcionamento só têm valia em termos quantificáveis. Tal postulado então admitido pela nova gestão pública faz-se imprescindível, pois, para o padrão organizacional em questão, "sem resultados mensuráveis (que devem ser tornados públicos) não se consegue estabelecer uma base de responsabilização credível, tornando-se igualmente mais difícil a promoção da competição entre sectores e serviços" (Afonso, 2009, p. 119).

Essas são, com efeito, algumas das principais orientações que têm tipificado esse modelo as quais, a partir do momento que passam a ser aplicadas na esfera educacional, têm suas consequências na organização e funcionamento dos serviços públicos educacionais, bem como no nível das interações que se desenvolvem no meio educacional, da educação básica ao ensino superior.

No Brasil, com linhas mestras traçadas pela União, tal modelo também vem sendo sistematicamente aderido por governos estaduais e municipais, no que diz respeito à gestão da educação. No Rio Grande do Norte a adesão explícita a esse modelo pelo Executivo estadual tem como marco o Projeto Integrado de Desenvolvimento Sustentável do Rio Grande do Norte - RN Sustentável. Orçado no valor de quatrocentos milhões de dólares o RN Sustentável constituiu-se num plano de modernização do Estado do Rio Grande do Norte que ganhou impulso na referida realidade a partir de 2013, em face do acordo de empréstimo n. 8276-BR, junto ao Banco Internacional para Reconstrução e Desenvolvimento - Bird -, no total de trezentos e sessenta milhões de dólares.

Tal empréstimo foi estabelecido na gestão de Rosalba Ciarlini Rosado (2011-2014), sendo a reforma multissetorial prevista pelo Projeto RN Sustentável continuada pelas gestões de Robinson Mesquita de Faria (2015-2018) e de Maria de Fátima Bezerra (20192022). Isso posto, parece-nos importante alinhavar que o Banco Mundial de maneira nenhuma exerce papel coadjuvante nesse projeto, uma vez que tal banco tem sido um dos organismos indutores de reformas dessa natureza e da adesão aos postulados do modelo gerencial em países de todo o mundo, incluindo o Brasil.

Tendo isso em vista, a presente análise se propõe a abordar aspectos estruturantes da reforma educacional deflagrada pelo Projeto RN Sustentável, dando realce ao conjunto de ações então previstas para o setor educativo, situando, entre essas medidas, a implantação do Sistema Integrado de Monitoramento e Avaliação Institucional da Secretaria de Estado da Educação do Rio Grande do Norte - Simais. Para tanto, o estudo recorreu à pesquisa documental realizada em três sítios oficiais do Executivo estadual.

Inicialmente foi feita uma busca na página do Projeto RN Sustentável ${ }^{3}$, aba documentos, e no site do Projeto Governo Cidadão ${ }^{4}$, aba publicações, com ênfase para fontes documentais relativas ao planejamento da reforma administrativa em vigor no estado do Rio Grande do Norte. A terceira plataforma pesquisada foi o site oficial do

3 Disponível em: http://www.rnsustentavel.rn.gov.br/.

4 Disponível em: http://www.governocidadao.rn.gov.br/.

\begin{tabular}{l|l|l} 
Regae: Rev. Gest. Aval. Educ. & Santa Maria & v. 10
\end{tabular}

ก. 19

e67316, p. 1-17

2021 
governo do Rio Grande do Norte ${ }^{5}$, em que, na opção de pesquisa da referida página, buscou-se pelo assunto "Simais", optando-se pelo filtro "Todos": matérias, vídeos, imagens, documentos e links. Nesse terceiro acesso também foi efetivada uma varredura no Diário Oficial do Estado, com restrição das buscas entre janeiro de 2016 e dezembro de 2020, fazendo uso da mesma palavra-chave "Simais". Por fim, também foi feita a busca por informações no site do Simais ${ }^{6}$.

Com isso, o corpus documental selecionado foi composto por portarias, atos administrativos, revistas, notícias e documentos diversos. Nessa linha, foi justamente por meio da análise do material recolhido no percurso supracitado que se buscou atender ao objetivo visado neste estudo, a partir de três tópicos consecutivos: Projeto RN Sustentável, Projeto Governança Inovadora, Sistema Integrado de Monitoramento e Avaliação Institucional da Secretaria de Estado da Educação do Rio Grande do Norte.

\section{Projeto RN Sustentável}

O enredo da reforma educacional endereçada à rede estadual de ensino básico do Rio Grande do Norte teve sua origem no Projeto RN Sustentável, que consiste num plano de reestruturação do Estado do Rio Grande do Norte, financiado em maior parte com recursos oriundos de um empréstimo junto ao Banco Mundial no ano de 2013: acordo de empréstimo internacional n. 8276-br).

Conforme consta em seu manual operativo, o Projeto RN Sustentável foi concebido com o propósito de "reverter o cenário de baixo dinamismo socioeconômico regional do estado e apoiar ações de modernização da gestão do setor público para prestação de serviços de forma mais eficaz e eficiente" (Rio Grande do Norte, 2013, p. 2). Como se nota, guardando forte relação com as orientações do Banco Mundial e com os princípios da nova administração pública, no âmbito desse projeto o Estado do Rio Grande do Norte aderiu ao modelo de gestão por resultados, assumindo três grandes eixos estratégicos: o desenvolvimento regional sustentável, a melhoria dos serviços públicos e a melhoria da gestão do setor público.

Assim, no corpo desse documento evidencia-se a preocupação com a infraestrutura socioeconômica do Estado, havendo a previsão de investimentos nos planos socioambientais e produtivos. Paralelamente a isso a saúde, a educação e a segurança pública são exaltadas como campos prioritários de intervenção, para fins de uma pretensa melhoria do acesso e da qualidade dos serviços ofertados.

O prelúdio da reforma no campo educacional, que é a que interessa à presente análise, é localizado no segundo componente estratégico do Projeto RN Sustentável melhoria dos serviços públicos -, e o escopo para essa área consiste em apoiar "a estratégia do Estado na agenda de desenvolvimento regional integrado e no desempenho educacional dos alunos e escolas" (Rio Grande do Norte, 2013, p. 68). Com isso em mente foram propostos dois grupos de atividades: o primeiro grupo é direcionado à integração da educação à agenda de desenvolvimento regional, enquanto o segundo se apresenta em prol da melhoria dos processos de ensino-aprendizagem.

5 Disponível em: http://www.rn.gov.br/.

6 Disponível em: em: https://simais.caedufjf.net/.

Regae: Rev. Gest. Aval. Educ. Santa Maria v. 10 ก. 19 e67316, p. 1-17 2021 
Em síntese, o primeiro grupo compreende uma série de medidas complementares ao Programa Nacional de Educação do Campo - Pronacampo - e ao Programa Nacional de Acesso ao Ensino Técnico e Emprego - Pronatec. Nesse sentido, tal projeto se põe à disposição para custear ações voltadas à construção de seis escolas no campo, à alfabetização de 12,5 mil jovens e adultos residentes na área rural, ao fomento ao ensino técnico-profissional orientado às demandas da cadeia produtiva e ao apoio à agricultura familiar para fins de sua incorporação no Programa Nacional de Alimentação Escolar Pnae. O segundo grupo, por sua vez, é composto por cinco atividades. A primeira atividade equivale à elaboração de diretrizes e matrizes curriculares para a rede pública de ensino norte-rio-grandense, tanto para o ensino fundamental, quanto para o ensino médio. Para isso o projeto prevê recursos para a contratação de consultoria especializada, bem como para a formação continuada voltada à implementação de tais diretrizes nas escolas, dentre outras ações.

A segunda atividade compreende o Projeto de Inovação Pedagógica - PIP -, que se propõe a melhorar a gestão e o desempenho das escolas. Em termos práticos o PIP é uma ação de fomento ao desenvolvimento de projetos escolares por parte das unidades de ensino, desde que sejam voltados à solução de problemas de gestão ou de caráter pedagógico, que atuam negativamente sobre o desempenho do alunado e da escola.

Nesse sentido, o documento é peremptório ao ressaltar que, na proposição desses projetos, as instituições de ensino devem se preocupar em "atingir metas de fortalecimento da gestão pedagógica, do Conselho Escolar, da autonomia da escola e de sua responsabilidade em relação a resultados significativos de aprendizagem" (Rio Grande do Norte, 2013, p. 71). Em seu desenho o PIP prevê a liberação de recursos anuais por cada projeto de inovação pedagógica, com verbas que vão de quatro a dez mil reais. Tal atividade inclui ainda o financiamento de outras ações relacionadas à execução do referido projeto.

Em outra frente, o conjunto de medidas do grupo que se põe a favor da melhoria do ensino e da aprendizagem situa os mecanismos de avaliação e monitoramento da rede de ensino. Assim, em sua atividade terceira, tal grupo compromete-se com a implantação do que foi denominado de Sistema de Avaliação da Educação Básica e Profissional do Rio Grande do Norte - SAB/RN. No mais, também seria intenção dessa linha de atuação investir no Observatório da Vida do Estudante da Educação Básica - Oveeb.

O SAB/RN foi o nome inicialmente atribuído ao que, em 2015, foi denominado de Sistema de Monitoramento e Avaliação Educacional - Sima-EB - e que, em 2016, foi finalmente cognominado de Simais, quando o referido sistema de avaliação é instituído pelo governo do Estado. No Manual operativo do Projeto RN Sustentável - em que foram feitas as primeiras formulações sobre o sistema próprio de avaliação da educação básica -, tal mecanismo teria o "objetivo de monitorar e avaliar a qualidade da educação básica e avaliação de programas de educação profissionalizante" (Rio Grande do Norte, 2013, p. 72).

Já o Oveeb seria pensado com o fito de "garantir o acompanhamento do desempenho escolar dos alunos da rede estadual" (Rio Grande do Norte, 2013, p. 72). Como bem esclarece o documento, tal observatório consistiria num órgão específico para a realização de estudos e análises sobre o corpo discente pertencente à rede estadual de ensino. Ademais, o Oveeb também é caracterizado como um instrumento de 
accountability, uma vez que, além do acompanhamento do aluno, em consonância com o referido documento, por meio do Oveeb seria efetivada uma prestação de contas dos trabalhos da secretaria de educação, também sendo um meio de viabilizar a participação da sociedade em processos decisórios.

$\mathrm{Na}$ quarta atividade, o projeto posiciona o Programa de Desenvolvimento dos Padrões Mínimos da Escola, advogando que "a melhoria da qualidade da educação requer também que as escolas ofereçam um mínimo de qualidade em sua infraestrutura, recursos humanos, equipamento e mobiliário" (Rio Grande do Norte, 2013, p. 72). É interessante notar que esse programa, apesar de ter um formato afinado com o debate em torno do custo aluno-qualidade com bastante visibilidade no campo educacional nesse período, em nenhum momento o cita, nem se demonstra suscetível a adotar a sua metodologia. Pelo contrário, segundo o referido documento, os critérios e padrões mínimos eram aspectos a serem definidos de acordo com a etapa e a modalidade de ensino ofertadas na escola.

No âmbito desse programa, além dos serviços de consultoria, de elaboração e de reprodução dos manuais de padrões mínimos, constam, para serem custeadas, a construção de instituições de ensino médio, a ampliação de 35 escolas e a restauração de 60 unidades de ensino, lado a lado à disponibilização de mobiliário e equipamentos para todas as escolas da rede (Rio Grande do Norte, 2013). Por fim, a quinta atividade desse conjunto de ações foi denominada de Criação de Regime de Colaboração EstadoMunicípio.

Partindo do argumento de que "a fragilidade dos municípios tem uma repercussão direta sobre o desempenho educacional de todo o estado nas avaliações nacionais" (Rio Grande do Norte, 2013, p. 73), essa atividade pretende induzir a Secretaria Estadual de Educação a oferecer "apoio técnico aos municípios voltado à adoção de políticas comuns para a melhoria da qualidade da educação e a definição de um padrão mínimo de qualidade para a rede pública" (Rio Grande do Norte, 2013, p. 73). Como parte dessa ação seriam destinados recursos para financiar o programa de apoio às municipalidades, a promoção de eventos de capacitação e a realização de fóruns regionais, também sendo enfatizados 0 apoio na elaboração de planos municipais de educação e o desenvolvimento de um plano estratégico visando repassar a incumbência por determinadas modalidades de ensino aos municípios.

Passados alguns anos em que as medidas supramencionadas para o campo da educação foram pensadas, o presente estudo não almeja evidenciar quais delas efetivamente se concretizaram, sendo isso matéria para estudos futuros. Dentre as ações listadas, como já se antecipou, o que se pretende pôr em realce neste trabalho é a implementação do Sistema Estadual de Avaliação da Educação Básica, denominado no corpo do referido projeto de SAB/RN.

Voltando à reforma educacional propriamente dita e à série de ações que a compõe, salta aos olhos a preocupação com os resultados educacionais da rede estadual de ensino, especialmente os que se evidenciam por intermédio das avaliações externas e em larga escala. Tal direcionamento se manifesta, mais precisamente, entre as atividades do 
segundo grupo de trabalho, perpassando-as e alinhavando-as. Por sinal, o alinhamento dessas ações e o ponto em comum entre elas são reforçados ou percebidos de modo mais nítido quando se analisam os principais resultados esperados com o Projeto RN Sustentável.

No parágrafo em específico do referido documento que disserta a esse respeito, no que compete particularmente à educação, dentre todas as respostas possíveis de serem elencadas, a que ganha destaque é a "melhoria do índice da educação básica do ensino secundário (Ideb)" (Rio Grande do Norte, 2013, p. 28). Além disso, em outro ponto mais avançado do texto, apresentam-se como objetivos "corrigir progressivamente a distorção idade/série nos anos iniciais e finais do Ensino Fundamental, melhorar o desempenho dos professores e alunos e garantir a qualidade da educação" (Rio Grande do Norte, 2013, p. 38).

Além da questão da oferta prioritária dessa etapa da educação básica pelo estado, a ênfase no Índice de Desenvolvimento da Educação Básica - Ideb - do ensino médio guarda relação com os baixos resultados que tal ente federado vinha obtendo nesse indicador. Como analisado por Cabral Neto e Castro (2019), nessa realidade todas as notas do Ideb, no período de 2005 a 2015, ficaram abaixo das médias nacional e regional. A situação revela-se igualmente preocupante quando se observa a problemática da distorção idade/série, que nessa etapa mantém-se superior às taxas registradas no Nordeste e no Brasil entre os anos de 2011 e 2015, consoante posto a nu por tais pesquisadores.

Nessa linha, para o campo educacional, como indicadores de focalização, o projeto elegeu a nota do Ideb nos anos iniciais e finais do ensino fundamental, a taxa de alfabetização da população com 15 anos ou mais e a distorção idade/série, tanto no ensino fundamental, quanto no ensino médio, tendo como referência a base de dados do Inep de 2011 e a da própria Secretaria de Estado da Educação e da Cultura do Estado do Rio Grande do Norte concernente ao ano de 2010. O Manual operativo do projeto sinaliza que

as ações propostas no Projeto RN Sustentável para a área da educação têm objetivos, metas e prazos bem definidos. Para atingi-los é necessária uma boa sistemática de acompanhamento, controle e avaliação, [...] objetivando registrar e informar a operacionalização e implementação do Projeto nas escolas públicas, bem como apresentar os resultados da gestão e, principalmente, do desempenho dos alunos. (Rio Grande do Norte, 2013, p. 38)

Como é corrente em reformas desse tipo, também na proposta pensada para a educação básica do Estado do Rio Grande do Norte ${ }^{7}$, traça-se uma conexão direta entre qualidade da educação e desempenho do alunado em mecanismos de avaliação externa e em larga escala, com uma valorização desses resultados e com a aposta no monitoramento, na regulação, na avaliação de desempenho e no estabelecimento de metas, estando todos subjugados aos objetivos supostamente buscados com essa reforma.

\footnotetext{
7 Movimento que vem sendo enxergado por Torres (2001, p. 79) como "a uniformização da política educativa em escala global", estando "vinculada ao crescente peso dos organismos internacionais no projeto e na execução da política educativa nos países em desenvolvimento".

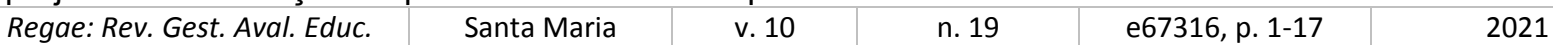




\section{Projeto Governança Inovadora}

Na gestão de Robinson Faria indicativos do prosseguimento dessas ações no setor educativo são evidenciados no âmbito do Projeto Governança Inovadora, que se ramifica como ação estratégica com vistas a contribuir com a agenda de modernização da gestão pública no cerne do Estado do Rio Grande do Norte, fazendo alusão explícita ao Projeto RN Sustentável, assim como ao acordo de empréstimo supracitado. Como elucidam Torres et al. (2016, p. 18), "o Governança Inovadora está inserido no âmbito do Projeto RN Sustentável".

O Projeto Governança Inovadora foi instaurado em agosto de 2015, ou seja, no início do segundo semestre do governo de Robinson Faria, no formato de um planejamento estratégico voltado ao Estado do Rio Grande do Norte, para um período de 20 anos que, não por acaso, reitera a preocupação com o desenvolvimento sustentável da unidade federativa. Isso porque os objetivos então relacionados ao desenvolvimento sustentável presentes no Governança Inovadora, bem como no RN Sustentável, encontram-se alinhados à Agenda 2030 para o Desenvolvimento Sustentável da Organização das Nações Unidas, adotada por países de todo o mundo.

No tocante ao setor educativo o Governança Inovadora recupera o conteúdo de algumas das pretensões presentes no Projeto RN Sustentável relativas a essa área. Num dos principais documentos atrelados ao Governança Inovadora (Marini et al., 2016), que trata especificamente da elaboração de um Plano Estratégico de Desenvolvimento do Estado até o ano de 2035, renova-se a preocupação com a elevação dos índices de alfabetismo entre pessoas pertencentes a diferentes faixas de idade, com a diminuição da distorção idade/série e com a expansão da oferta de educação profissional, acrescentando ainda como objetivo oferecer educação em tempo integral em $50 \%$ das escolas da rede estadual de ensino.

Maior detalhamento e informações adicionais da reforma educacional no Rio Grande do Norte são fornecidos no documento Governança inovadora em ação: processos redesenhados (Torres et al., 2016), que aborda o que passa a ser prioridade para o setor educacional: os objetivos buscados, as atividades a serem desenvolvidas, as estratégias de avaliação e acompanhamento e os resultados esperados. Em síntese, no âmbito desse material são destacados como alvos prioritários de atuação da Seec: implementação de diretrizes curriculares; implementação do plano estadual de educação; comunicação escolas - diretoria regional de educação e cultura - secretaria; organização do trabalho pedagógico; formação continuada dos profissionais de educação e avaliação do processo de ensino e aprendizagem.

O processo intitulado implementação das diretrizes curriculares tem por objetivo implementar diretrizes curriculares estaduais em todas as escolas e centros educacionais norte-rio-grandenses. Como parte dessa finalidade pretende-se alinhar o que se deve ensinar e o que se deve aprender junto ao corpo docente, que atua nas diferentes etapas e modalidades de ensino, sendo isso colocado como um objetivo a alcançar. Também é posto que tais diretrizes devem se referenciar na Base Nacional Curricular Comum, assim como no PEE, devendo ser tema de formação junto às Direcs e aos profissionais de educação básica. Ademais, cada escola é instada a ajustar seu projeto políticopedagógico a tais diretrizes, sendo tal alinhamento destacado como o indicador de acompanhamento desse processo (Torres et al., 2016).

Santa Maria

v. 10

n. 19

e67316, p. 1-17

2021 
Outro objetivo prioritário para o campo educacional consiste em assegurar a implementação do PEE, lei n. 10.049, de 27 de janeiro de 2016, prevendo, para tanto, que os planos de gestão das escolas, como também os planos de ação das Direcs e da Secretaria Estadual de Educação se adéquem ao PEE. Tal processo também dá ênfase ao monitoramento e à avaliação da execução dos planos de gestão por parte das escolas e centros. De outro lado, em função desse objetivo, há um destaque para um plano de formação continuada para a equipe gestora com unidades formativas que contemplem a temática administrativa, pedagógica e financeira, apontando também processos de avaliação nesse nível. Por fim, tal documento prescreve ainda a avaliação do impacto do PEE por intermédio da plataforma do Simais, envolvendo a recolha de dados do Inep e de informações relativas à execução dos planos de gestão (Torres et al., 2016).

No bojo do Projeto Governança Inovadora também é de crucial importância a comunicação entre a Secretaria, as Direcs e as unidades de ensino, para fins de atender a eventuais demandas apresentadas por escolas e centros de educação. Nessa linha, de modo a terem suas necessidades atendidas, em consonância com Torres et al. (2016), escolas e centros devem recorrer ao Sistema Integrado de Gestão da Educação - Sigeduc -, para então solicitar, mediante apresentação de objetivo e de justificativa, atendimento de sua demanda. Além de fortalecer a comunicabilidade, a ideia manifesta é fazer com que as necessidades das instâncias locais sejam atendidas de forma ágil e efetiva.

O documento apresenta um organograma da tramitação da demanda, da inserção pelas instituições de ensino ao seu encaminhamento e da eventual resolução pelos setores responsáveis. Diferentemente de outras ações, nesse período, o Sigeduc já era uma realidade no Estado, tendo sido implantado no ano de 2012 e já se constituindo em objeto de análise de outros estudos, como os que são citados por Cabral Neto e Castro (2019).

Outra dimensão primordial ao setor educativo refere-se ao que foi denominado de organização do trabalho pedagógico. Esse processo tem por objetivo "fomentar o planejamento das formas de organização, estruturação e gestão das escolas e centros" (Torres et al., 2016, p. 221). A anuncia-se um movimento de orientar a atualização do PPP das escolas, adequando-o à agenda educacional do Estado que inclui o PEE, as diretrizes curriculares, a avaliação de desempenho escolar e a formação continuada dos profissionais de educação. Nesse ponto também se faz menção ao que vem sendo denominado de Referências Básicas para Orientação do Trabalho Pedagógico - RBOTP -, que estavam em elaboração nessa época. É assim que, no organograma proposto, com a atualização do PPP necessariamente articulada às dimensões supracitadas, fala-se num 'PPP adequado', assim como no monitoramento e na avaliação de suas ações.

Tudo isso, como se observa, desemboca na formação continuada dos profissionais de educação. Segundo Torres et al. (2016) o processo voltado ao planejamento, execução, avaliação e monitoramento da formação do quadro que compõe tal categoria tem como ponto de partida a elaboração de um Plano Estadual de Formação, sucedido por planos regionais e escolares, tendo o plano estadual como parâmetro, mas adaptando-se à realidade a que se destinam. Além do PEE, o plano estadual para 
formação desses profissionais deveria se pautar numa avaliação do ano letivo feita a partir da análise dos resultados das avaliações internas e externas, das demandas apresentadas pelas instituições de ensino e pelas Direcs, dos PPPs e dos planos de ação das escolas, bem como da implementação do PEE e das diretrizes curriculares estaduais.

Finalmente, no que compete à avaliação do processo de ensino e aprendizagem, o Governança Inovadora reporta-se, tanto à avaliação da aprendizagem escolar propriamente dita, quanto às avaliações externas. No que tange à avaliação interna vincula sua realização às escolas e aos centros de educação, orientando que a avaliação do desempenho do estudante se faça por intermédio de instrumentos variados: observação, prova, teste, observação, assiduidade.

No eixo da avaliação externa, além de um trabalho voltado à interpretação dos dados da avaliação, tem-se como finalidade analisar a relação do currículo escolar com as matrizes de referência dessas avaliações (Torres et al., 2016), o que tende a implicar a regulação do trabalho escolar, incluindo o que deve ser ensinado, o que deve ser avaliado e até como deve ser avaliado, contrapondo-se, portanto, às expectativas que se criam em torno da avaliação da aprendizagem. O objetivo anunciado aqui consiste em "realizar a avaliação do processo de ensino e aprendizagem gerando insumos para a formulação de estratégias de intervenções didático-pedagógicas" (Torres et al., 2016, p. 229).

No mais, a ideia também é que os resultados das avaliações se tornem subsídios para a elaboração e implantação de políticas educacionais. Esse campo de atuação prioritário reveste-se, assim, como mecanismo de prestação de contas, listando ainda a preparação de apresentações e relatórios específicos endereçados aos três níveis de gestão - Seec, Direc, escola -, aos professores, às famílias e à sociedade civil. Essa última área de atuação não faz menção explícita ao Simais, ainda assim, é notável o espaço conferido à Subcoordenadoria de Avaliação Educacional - Suave -, órgão do Executivo estadual que desde o ano de 2016 teve suas funções alinhadas à realização do Simais.

Apesar de integrarem um mesmo projeto e de convergirem para objetivos comuns, com algumas de suas principais questões correspondentes, em linhas gerais não há uma equivalência direta e fiel entre o que se propõe no RN Sustentável e o que está posto pelo Governança Inovadora. Tomando de empréstimo o título de um dos documentos aqui referenciados, com o Governança Inovadora tem-se um redesenho nas ações projetadas para o campo educacional.

Sobressai-se, em todo caso, a ênfase na proposição e implantação de diretrizes curriculares estaduais, que devem dar o tom da formação continuada dos profissionais da educação, do PPP das escolas, estando mancomunadas ao sistema de avaliação da rede estadual de ensino. Evidentemente a estrutura presente no projeto como um todo confere as bases para o fortalecimento da regulação e do controle da escola, do ensino e da aprendizagem, em consonância com os fins visados pelo governo do Rio Grande do Norte.

A avaliação de desempenho, do mesmo modo, tem função medular na reforma educacional em curso. No RN Sustentável são as avaliações externas e os seus resultados dois dos principais referenciais da reforma pretendida, cujo ordenamento vibra a favor da elevação do desempenho educacional do Estado. Já no Governança Inovadora, de um lado, nota-se que o planejamento proposto também valoriza as avaliações externas, 
fazendo isso sob quatro vertentes, com o aproveitamento destas ou de seus resultados: para orientar o plano de formação continuada dos profissionais da educação; para nortear o currículo escolar; para ancorar o desenvolvimento de políticas educacionais e para situálas no plano das metas a serem atingidas. Por outro lado, planejamento lança mão de uma série de estratégias de avaliação específicas para acompanhar e induzir o alcance dos objetivos buscados o que, na realidade, endossa a premissa do RN Sustentável de acompanhamento, avaliação e controle.

De toda forma, há indicativos de adesão ao modelo de gestão por resultados pelo Estado do Rio Grande do Norte, sendo tal centralidade dos resultados da avaliação no planejamento estratégico esboçado uma clara evidência da incorporação desse modo de fazer gestão. Foi, portanto, em meio a essa conjuntura que se implantou o Simais no Estado norte-rio-grandense, como parte estruturante de um projeto de modernização gerencialista, constituindo-se como porta de entrada para a implementação de mecanismos de responsabilização educacional na rede estadual de ensino, como discutiremos na próxima seção.

\section{Sistema Integrado de Monitoramento e Avaliação Institucional da Secretaria de Estado da Educação do Rio Grande do Norte}

No Estado do Rio Grande do Norte o investimento num sistema de avaliação externa próprio foi uma demanda nascida com o RN Sustentável. Dado o entrelaçamento desse projeto com o Bird, convém lembrar, como analisam Santos e Sabia (2015), que é típico desse organismo orientar "a constituição de sistemas de avaliação fortemente centralizados, remetendo ao governo central a tarefa de fiscalização e proposição de aprimoramentos administrativos e curriculares" (p. 357). Logo, a proposição de sistema próprio de avaliação não se deu sem a existência de outros arranjos, tampouco por propósitos exclusivamente educacionais.

Assim sendo, institucionalmente, em documentos oficiais relativos ao sistema, reiteram-se alguns dos principais argumentos e traços característicos da reforma educacional em curso. Para ser mais preciso, desde a primeira edição, tal sistema tem sido anunciado como instrumento para aferir a qualidade do ensino ofertado na rede estadual de ensino básico (Rio Grande do Norte, 2017d, 2018b, 2019c; Suave, 2016), estando orientado para a produção de indicadores educacionais para subsidiar a formulação e implementação de políticas públicas com vistas à elevação do desempenho do sistema público de ensino e ao desenvolvimento da educação estadual (Rio Grande do Norte, 2016b, 2017c, 2017e, 2018c, 2019c, 2019a, 2019b).

Pistas nesse sentido também são obtidas nas Revistas do Sistema e do Gestor Escolar, relativas à edição de 2018, ao revelarem que a Seec vem implementando medidas voltadas à oferta de uma educação de qualidade à luz dos resultados e indicadores proporcionados pelo Simais. Dentre essas medidas estariam 0 aperfeiçoamento dos processos de gestão escolar, a definição de diretrizes curriculares estaduais, a reestruturação da formação continuada dos profissionais da educação, 0 investimento na infraestrutura das escolas, entre outras ações.

Como se nota, vê-se a todo momento o intercruzamento do Simais com outras frentes tidas como prioritárias para o estado no período que vai até o ano 2035. Nessa linha, conforme se acentua em duas portarias (Rio Grande do Norte, 2018c, 2019c) que

\begin{tabular}{|l|l|l|l|l|r|}
\hline Regae: Rev. Gest. Aval. Educ. & Santa Maria & v. 10 & n. 19 & e67316, p. 1-17 & 2021
\end{tabular}


regimentaram a realização do sistema nos anos de 2018 e 2019, cabe ao Simais e aos seus resultados nortear a política educacional do Estado, em atenção às metas do PEE em vigor. No PEE a avaliação figura tanto entre as suas dimensões - artigo $2^{\circ}$, inciso II -, quanto entre suas metas e estratégias - meta 3 , estratégia nona -, relativas à qualidade da educação básica.

Com aceno a uma noção restrita de qualidade educacional, a terceira meta do referido plano consiste em "fomentar a qualidade da Educação Básica em todas as etapas e modalidades, com melhoria do fluxo escolar e da aprendizagem" (Rio Grande do Norte, $2016 a$, p. 15), visando à obtenção de determinadas notas do Ideb até 2025, indo, portanto, além das metas instituídas pela União, que, até então, só vão até o ano de 2021. Das estratégias para tanto tem-se a implementação da autoavaliação das escolas das redes públicas de ensino.

Por fazer alusão a "um processo contínuo de autoavaliação das escolas" (Rio Grande do Norte, 2016a, p. 16), tal estratégia não apresenta claramente a que tipo de avaliação se refere, abrindo espaço para interpretações dúbias e para questionamentos sobre o que, de fato, tal colocação pretendia expressar. Malgrado as dúvidas que tal redação gera, em janeiro de 2016 o PEE foi aprovado e, no segundo semestre desse ano, - Simais foi instituído, tendo inicialmente como componentes a avaliação do desempenho acadêmico e a avaliação institucional da rede estadual de ensino, ambas com caráter externo e em larga escala.

Assim sendo, o primeiro eixo do Simais está voltado para a avaliação do desempenho dos alunos, realizada por intermédio do Programa RN Aprende, aplicado censitariamente em séries específicas dos ensinos fundamental e médio da rede estadual que, na primeira edição, teve como objetivo diagnosticar os níveis de proficiência dos estudantes nas áreas de Matemática, Língua Portuguesa, Ciências Humanas e Ciências da Natureza. Apesar desse objetivo inicial, a partir de 2017 os componentes curriculares avaliados foram reduzidos a Língua Portuguesa e Matemática, também havendo mudanças nos anos de escolaridade abrangidos.

Como já destacado, a princípio, introduziu-se também, por meio do Simais, uma avaliação institucional, levantando dados relativos a fatores internos e externos à rede estadual de ensino. Com isso, no memorando circular n. 74, de 26 de setembro de 2016, que versa sobre a primeira edição do sistema, a Secretaria Estadual de Educação se reportou à aplicação de questionários específicos referentes à avaliação institucional, contemplando alunos, professores, gestores e equipe técnica das escolas, das Direcs, das Diretorias Regionais de Alimentação Escolar e da Seec.

Diferentemente do observado em 2016 três fontes documentais concernentes à edição de 2017 (Rio Grande do Norte, 2017a, 2017b, 2017e) situam a tônica na avaliação dos estudantes, sem mencionar a aplicação de questionários. Todavia, a Revista do Gestor Escolar (Rio Grande do Norte, 2018d) dá a entender que, a partir de 2017 os questionários passaram a ser destinados apenas a professores e gestores escolares.

Maior esclarecimento a esse respeito veio somente em 2018, por ocasião da portaria n. 1.727/2018-SEEC/GS, de 20 de novembro, que se reporta a questionários contextuais endereçados a alunos e professores dos componentes e anos de escolaridade avaliados, como também a diretores e instituições escolares. A essa altura, o espaço da avaliação 
institucional já tinha sido cedido para uma avaliação mais restrita - a avaliação do contexto escolar -, sendo a primeira uma experiência certamente desenvolvida na edição inaugural do Simais.

Posto isso, talvez a forma que o Simais vem assumindo possa servir, portanto, para clarificar o que o PEE quis dizer com autoavaliação das escolas. De qualquer forma, no detalhamento da estratégia supramencionada, além da melhoria da qualidade da educação, o PEE vincula tal avaliação à formação continuada e ao aperfeiçoamento da gestão democrática, importando salientar que, para o plano, gestão democrática compreende "participação, responsabilização e autonomia dos sistemas de ensino" (Rio Grande do Norte, 2016a, p. 2).

A esse propósito vale a pena pôr em realce que, até o ano de 2019, data da última edição do sistema, que vinha sendo aplicado anualmente até o cenário imposto pela pandemia de Covid-19 no ano de 2020, o Estado do Rio Grande do Norte não havia implantado nenhuma política de responsabilização pautada no desempenho dos alunos nos testes aplicados por tal sistema de avaliação. Similar análise também foi feita por Cabral Neto e Castro (2019), os quais asseveram que "esse sistema de avaliação, até o ano de 2018, não estava vinculado à distribuição de bônus de produtividade à escola, tampouco aos docentes pelo desempenho alcançado nos exames" (p. 404).

Não obstante, a partir do ano de 2017 já foi possível localizar os primeiros sinais da adesão a políticas dessa natureza pelo Estado, isso porque, a partir da segunda edição do Simais a Secretaria Estadual de Educação lançou uma política de incentivo para aumentar a taxa de participação dos alunos na avaliação. Assim, se em sua primeira edição o Simais não esteve associado a nenhum tipo de prêmio ou bonificação, na ocasião da segunda edição do sistema, em 2017, a Seec divulgou que distribuiria premiações para as instituições da rede estadual de ensino de acordo com a taxa de participação de cada escola na referida sistemática avaliativa.

Nessa segunda edição a taxa de participação estabelecida para concorrer ao prêmio foi de, no mínimo, $60 \%$ dos alunos matriculados na $3^{\text {a }}$ série do ensino médio, sendo premiadas as 50 unidades de ensino com os mais altos índices de participação. Como prêmio a Seec recorreu à oferta de kits educacionais de dois tipos: multimídia, formado por um projetor, uma tela retrátil e um notebook; e esportivo, composto por rede de vôlei, mesa e bola de tênis de mesa, raquete e bolas de vôlei, de futebol e de futsal (Rio Grande do Norte, 2017e). A divulgação dos nomes das escolas premiadas foi realizada em meados de maio de 2018 numa cerimônia cuja programação também envolveu a difusão dos resultados do RN Aprende 2017 e a entrega simbólica de kits educacionais aos gestores de duas instituições de ensino.

Já no ano de 2018 a premiação não foi destinada somente às escolas, mas também às Direcs, havendo mudança no prêmio, bem como na exigência para obtê-lo. Para tanto, conforme nota publicada pelo governo do Estado (Rio Grande do Norte, 2018a), a escola deveria apresentar taxa de participação superior a $80 \%$, enquanto a diretoria deveria obter índice superior a $70 \%$, ademais, mais da metade das escolas vinculadas a tal regional também deveriam alcançar taxa superior a $80 \%$. Nesse ano, ofertaram-se como prêmio 44 smart TVs de 50 polegadas, sendo quatro para as regionais e as demais para as unidades de ensino que atingissem tais índices. 
Além disso, essa mesma edição do Simais também esteve atrelada a outra premiação, voltada especificamente para os estudantes de escolas da rede estadual de ensino. Com efeito, nesse ano foi lançado um concurso de vídeos pela Seec. Tendo por tema "Como você convidaria seus amigos para participar do RN Aprende-Simais 2018?", o certame foi aberto a três categorias: $5^{\circ}$ ano do ensino fundamental; $9^{\circ}$ ano do ensino fundamental; e $3^{\text {a }}$ série do ensino médio, premiando o primeiro e o segundo colocados de cada ano de escolaridade com certificação e vouchers, convertidos posteriormente em tablets.

No ano de 2019 as fontes consultadas não forneceram nenhum indício de prêmio associado ao sistema, o que se verificou foi apenas um relato de discussão desses dados no primeiro semestre de 2020. Na edição de 2019 interrompeu-se, portanto, a dinâmica de premiação constatada nos dois anos anteriores, o que pode ter relação com a mudança na gestão administrativa do Estado que, aparentemente, mantém o Simais, mas não dá continuidade à política de premiação até então percebida. Todavia, em que pese a evidenciada suspensão de estratégias dessa ordem, tendo em vista a lógica que fecundou tal sistema de avaliação, não é absurdo supor que, caso haja uma eventual retomada desses mecanismos de premiação, os prêmios concedidos passem a ser vinculados aos resultados no RN Aprende, já que há um expressivo esforço - no seio da reforma em curso - voltado à elevação dos níveis de desempenho da rede estadual de ensino.

\section{Considerações finais}

Dialogando com princípios que regem a nova gestão pública, o plano de reestruturação do Estado do Rio Grande do Norte e a reforma educacional compreendida nele têm incontestável alinhamento com a agenda global de desenvolvimento sustentável das Nações Unidas, pactuada por 193 países, incluindo o Brasil. Além de se articular à agenda de 2030 no tocante à educação, que é um dos setores ditos como prioritários no projeto de modernização da gestão pública do Estado norte-rio-grandense, as medidas e estratégias correspondentes a essa área seguem em conformidade com a política educacional brasileira, sendo postas como verdadeiros meandros em prol da melhoria da qualidade da educação.

Sob a influência do Banco Mundial a reforma então proposta ao campo educacional tem por base a definição de padrões e de seus respectivos mecanismos de avaliação e monitoramento, que acabam difundido uma concepção limitada de qualidade educacional. Pela leitura que pode ser efetuada a qualidade da educação buscada pela reforma em curso deve, necessariamente, refletir-se na elevação de determinados índices educacionais, notadamente os que se referem à distorção idade/série, à alfabetização de jovens e adultos e, sobretudo, ao desenvolvimento da educação básica.

Dentre as ações pensadas nessa direção a avaliação é o instrumento que permitirá não só acompanhar como também chegar aos objetivos pretendidos. É nesse contexto que é germinada a ideia de um sistema de avaliação próprio, implantado no ano de 2016 , que tem sido uma das expressões mais representativas da reforma educacional em andamento, haja vista sua função dentro do planejamento estratégico adotado e seu entrosamento com os fins perseguidos pela reforma, especialmente por se localizar no núcleo atinente ao desempenho dos estudantes em avaliações estandardizadas, tal como por viabilizar processos e políticas de prestação de contas e responsabilização educacional. 
A esse propósito cumpre sinalizar que, ainda que encerradas, as experiências de premiação associadas a determinados dados provenientes do Simais, futuramente podem vir a ser base para a implantação de políticas de bonificação e premiação pautadas nos resultados de desempenho acadêmico dos estudantes. Esse é claramente um risco que se corre, principalmente ao se considerar a matriz ideológica da reforma educacional em vigor e seu contumaz apelo em torno da elevação dos resultados do estado nas avaliações externas. De qualquer forma, essa é uma questão que merece ser acompanhada nos próximos anos, o que se aplica, mormente, à reforma educacional em curso no Estado do Rio Grande do Norte, que reclama por estudos, análises e discussões que a abordem em sua totalidade ou que se delineiem com foco numa ou mais das dimensões que a tipificam.

\section{Referências}

ABRUCIO, Fernando Luiz. Os avanços e os dilemas do modelo pós-burocrático: a reforma da administração pública à luz da experiência internacional recente. In: PEREIRA, Luiz Carlos Bresser; SPINK, Peter Kevin (org.). Reforma do Estado e administração pública gerencial. Rio de Janeiro: FGV, 2005, p. 173-200.

AFONSO, Almerindo Janela. Avaliação educacional: regulação e emancipação: para uma sociologia das políticas avaliativas contemporâneas. São Paulo: Cortez, 2009.

AFONSO, Almerindo Janela. Reforma do Estado e políticas educacionais: entre a crise do Estado-nação e a emergência da regulação supranacional. Educação \& Sociedade, São Paulo, v. 22, n. 75, 2001, p. 15-32.

CABRAL NETO, Antônio. Gerencialismo e gestão educacional: cenários, princípios e estratégias. In: FRANÇA, Magna; BEZERRA, Maura Costa (org.). Política educacional: gestão e qualidade do ensino. Brasília: Liber, 2009, p. 169-204.

CABRAL NETO, Antônio; CASTRO, Alda Maria Duarte Araújo. Política educacional no RN: diretrizes, trilhas percorridas e resultados. In: OLIVEIRA, Dalila Andrade; DUARTE, Adriana Maria Cancella; RODRIGUES, Cibele Maria Lima (org.). A política educacional em contexto de desigualdade: uma análise das redes públicas de ensino da região Nordeste. Campinas: Mercado de Letras, 2019, p. 381-414.

CASTRO, Alda Maria Duarte Araújo. Gerencialismo e educação: estratégias de controle e regulação da gestão escolar. In: CABRAL NETO, Antônio et al. (org.). Pontos e contrapontos da política educacional: uma leitura contextualizada de iniciativas governamentais. Brasília: Liber, 2007, p. 115-144.

HYPÓLITO, Álvaro Moreira. Reorganização gerencialista da escola e trabalho docente. Educação: Teoria e Prática, Rio Claro, v. 21, n. 38, 2011, p. 59-78.

INTERNATIONAL BANK FOR RECONSTRUCTION AND DEVELOPMENT. Loan agreement: Rio Grande do Norte Regional Development and Governance Project. Loan number 8276-BR. October 4, 2013.

LESSARD, Claude. O debate americano sobre a certificação dos professores e a armadilha de uma política educativa baseada em evidência. Linhas Críticas, Brasília, v. 15, n. 28, 2009, p. 63-94.

MARINI, Caio et al. Estratégia: Plano Estratégico do RN 2016-2035. Natal: Seplan, 2016. 
MOURA, Jéssica Morais de; NOBRE, Anna Cláudia dos Santos; NOGUEIRA, Gustavo. O modelo inovador de gestão adotado pelo Rio Grande do Norte, Brasil e o seu alinhamento com a Agenda 2030. CONGRESO INTERNACIONAL DEL CLAD SOBRE LA REFORMA DEL ESTADO Y DE LA ADMINISTRACIÓN PÚBLICA, 23, 2018. Anais ... Guadalajara: Universidade de Gualajara, 2018.

PAULA, Alisson Slider do Nascimento de; COSTA; Frederico Jorge Ferreira; LIMA, Kátia Regina Rodrigues. Accountability e o mosaico da política de avaliação da educação superior brasileira. Regae - Revista de Gestão e Avaliação Educacional, Santa Maria, v. 8, n. 17, 2019, p. 1-15.

RIO GRANDE DO NORTE. Avaliação medirá aprendizagem dos alunos da rede estadual de ensino. Natal: Secretaria de Estado da Educação e Cultura, 2019a.

RIO GRANDE DO NORTE. Avaliação medirá proficiência em Língua Portuguesa e Matemática de alunos. Natal: Secretaria de Estado da Educação e da Cultura, 2018a.

RIO GRANDE DO NORTE. Avaliação que mede aprendizagem dos alunos da rede estadual acontece amanhã (5). Natal: Secretaria de Estado da Educação e da Cultura, 2019b.

RIO GRANDE DO NORTE. Educação do estado promove capacitação para o Simais 2018. Natal: Secretaria de Estado da Educação e da Cultura, 2018b.

RIO GRANDE DO NORTE. Extrato publicação ao contrato n. 75/2017 - Seec e a Universidade Federal de Juiz de Fora. Processo n. 265336/2017-5 Seec/RN. Natal: Secretaria de Estado da Educação e da Cultura, 2017a.

RIO GRANDE DO NORTE. Lei n. 10.049, de 27 de janeiro de 2016: aprova o Plano Estadual de Educação do Rio Grande do Norte (2015-2025) e dá outras providências. Diário Oficial do Estado do Rio Grande do Norte, Natal, 28 jan. 2016a.

RIO GRANDE DO NORTE. Manual operativo do Projeto RN Sustentável. Natal: Secretaria de Estado da Educação e da Cultura, 2013.

RIO GRANDE DO NORTE. Portaria n. 1.727/2018-SEEC/GS, de 20 de novembro de 2018. Diário Oficial do Estado do Rio Grande do Norte, Natal, 21 nov. 2018c.

RIO GRANDE DO NORTE. Portaria SEI n. 357, de 8 de outubro de 2019: estabelece as diretrizes de realização do Sistema de Monitoramento e Avaliação Institucional da Rede Estadual de Ensino - SIMAIS, no ano de 2019. Diário Oficial do Estado do Rio Grande do Norte, Natal, 12 out. 2019c.

RIO GRANDE DO NORTE. RN Aprende mobiliza estudantes em todo o Estado. Natal: Secretaria de Estado da Educação e da Cultura, 2017b.

RIO GRANDE DO NORTE. RN lança Sistema Integrado de Monitoramento e Avaliação nesta terça. Natal: Secretaria de Estado da Educação e da Cultura, 2016b.

RIO GRANDE DO NORTE. Simais 2017: Sistema Integrado de Monitoramento e Avaliação Institucional da Seec. Juiz de Fora: UFJF, 2017c. v. 1.

RIO GRANDE DO NORTE. Simais 2017: Sistema Integrado de Monitoramento e Avaliação Institucional da Seec. Juiz de Fora: UFJF, 2017d. v. 3.

RIO GRANDE DO NORTE. Simais 2018: Sistema Integrado de Monitoramento e Avaliação Institucional da Rede Estadual de Ensino do Rio Grande do Norte. Juiz de Fora: UFJF, 2018d. v. 2. 
RIO GRANDE DO NORTE. Sistema de avaliação estadual mede desempenho de 25 mil alunos do ensino médio. Natal: Assessoria de Comunicação Social, 2017e.

SANTOS, Uillians Eduardo dos; SABIA, Claudia Pereira de Pádua. Percurso histórico do Saresp e as implicações para o trabalho pedagógico em sala de aula. Estudos em Avaliação Educacional, São Paulo, v. 26, n. 62, 2015, p. 354-385.

SEEC. Memorando circular n. 74, de 26 de setembro de 2016. Natal: Gabinete da Secretária, 2016.

SUAVE. RN Aprende: avaliação da aprendizagem escolar 2016 - Orientações às escolas. Natal: Seec, 2016.

TORRES, Maria Cristina Gonçalves et al. Governança inovadora em ação: processos redesenhados. Natal: Seplan, 2016.

TORRES, Rosa Maria. Educação para todos: a tarefa por fazer. Porto Alegre: Artmed, 2001.

Antônia Bruna da Silva é professora na Universidade do Estado do Rio Grande do Norte.

Orcid: http://orcid.org/0000-0001-8609-2257.

Endereço: Rua República do Peru, 1227 - 59607-420 - Mossoró - RN - Brasil.

E-mail: antoniabruna@uern.br.

Girlene Pereira da Silva é servidora na Prefeitura Municipal de Pereiro/CE.

Orcid: https://orcid.org/0000-0002-3094-7399.

Endereço: Sítio Caetano, s/n, zona rural - 63460-000 - Pereiro - CE - Brasil.

E-mail: girlenesilva@prof.edu.pereiro.ce.gov.br.

Os autores, coletivamente, realizaram a concepção, criação e consolidação do artigo.

Recebido em 22 de agosto de 2021.

Aceito em 24 de outubro de 2021.

(c) (1) $(9)$ 